\title{
MOISTURE DIFFUSIVITY IN HIGH OLEIC SUNFLOWER SEEDS AND KERNELS
}

\author{
Estela M. Santalla ${ }^{1}$ and Rodolfo H. Mascheroni ${ }^{2}$ \\ ${ }^{1}$ Facultad de Ingeniería UNCPBA. Programa Tecnología de Semillas, Universidad \\ Nacional del Centro de la Provincia de Buenos Aires, Olavarría, Argentina \\ ${ }^{2}$ CIDCA (CONICET-UNLP, La Plata, Argentina and MODIAL), Depto Ing. \\ Química, Facultad de Ingeniería, Universidad Nacional de La Plata
}

Moisture diffusivities in high oleic seeds and kernels were obtained from experimental thin layer drying rates in the range of $25-90^{\circ} \mathrm{C}$ air temperature and $4.2-33.5 \%$ initial moisture content (d.b.). Moisture diffusivity back-calculated from Fick's second law of diffusion varied between $0.85 .10^{-10}$ and $7.26 .10^{-10} \mathrm{~m}^{2} / \mathrm{s}$ for seeds and between $0.37 .10^{-10}$ and $2.39 .10^{-10}$ $\mathrm{m}^{2} / \mathrm{s}$ for kernels. The Arrhenius activation energy for seeds and kernels resulted 31 and $24 \mathrm{~kJ} / \mathrm{mol}$, respectively. A new model based on the kinetic parameter of Page equation was proposed as a simple tool to predict water diffusion in high oleic sunflower seeds and kernelss.

Keywords: Moisture diffusivity, Sunflower seeds, Kernels.

\section{INTRODUCTION}

Sunflower (Helianthus annuus L.) hybrid varieties are almost exclusively used for commercial oilseed production. Native sunflower oil is mainly used for human consumption since it contains a large amount of essential linoleic acid (w6 C18:2) which gives the sunflower seed oil a high nutritional value. In addition, high oleic' varieties have been obtained by chemical mutagenesis of accumulating oleic acid (w9 C18:1) up to $85 \%$ in the oil. ${ }^{[1]}$ This oil is nutritionally desired to increase the mono-unsaturated level in the diet. The possibilities of use of this oil are so widespread researchers consider that this differential oil from high oleic sunflower seeds will dominate the type of sunflower to be cultured. ${ }^{[2]}$ This grain is produced at a relative low volume and is still considered a special oilseed. The knowledge of the behavior of these modified grains, especially during post-harvest processing, is not yet available. Drying and storage processes can affect the oil quality of seeds as have been shown previously. ${ }^{[3]}$ The knowledge of drying kinetics contributes to keep the genuine quality of the oil because it is a tool for the proper design and selection of the equipment and operation conditions during post harvest processes. Moreover, diffusivity

Received 3 August 2008; accepted 17 November 2008.

Address correspondence to Estela M. Santalla, Facultad de Ingeniería UNCPBA. Programa Tecnología de Semillas Universidad Nacional del Centro de la Provincia de Buenos Aires, Av. Del Valle 5737. B7400JWI Olavarría Argentina. E-mail: esantall@fio.unicen.edu.ar 
is a transport property which accurate prediction can lead to optimisation of drying processes, especially in highly automated computer aided systems. ${ }^{[4]}$

Moisture diffusivity in traditional sunflower kernels and hulls were determined at 40 and $50^{\circ} \mathrm{C},{ }^{[5]}$ but no references have been found related to the variation of moisture diffusion with temperature and initial moisture content. Based on the above mentioned situation, the objectives of the present work were: to evaluate the moisture diffusivity of water in high oleic sunflower seeds and kernels; to identify the effect of air temperature; to predict activation energy; and to evaluate a new model to estimate the diffusion of water in seeds and kernels of high oleic sunflower based on the kinetic parameter of Page model.

\section{MATERIALS AND METHODS}

The evaluation of moisture diffusivity was carried out based on thin-layer drying experiments, as coefficients determined in this way can be used with confidence for scaling up and optimising industrial driers. ${ }^{[4]}$

\section{Sample Preparation}

Trisum 568 (Mycoyen-Morgan), a striated high oleic genotype of sunflower (Helianthus annuus L.) was selected to carry out this study. Ten bulk samples, each consisting of $5 \mathrm{~kg}$ of seed, were prepared from seeds produced at Oriente, Coronel Dorrego, Argentina, after 80 days of physiological maturity stage. The seeds were manually cleaned for foreign matter, broken and immature seeds. The initial moisture content of the seeds was $14.3 \%$ dry basis (d.b., g water/g dry solids). Whole kernels and hulls were both obtained by manual dehulling of the seeds. Seeds and kernels were packed separately in double-layered low-density polyethylene bags sealed and stored at low temperature $\left(5^{\circ} \mathrm{C}\right)$ in a refrigerator to reduce the rate of microorganisms growing. For each thin-layer drying test, the required amount of material was taken out and allowed to warm up to room temperature for approximately $2 \mathrm{~h}^{[6]}$

To evaluate the effect of initial moisture content on diffusion coefficient, samples of seeds and kernels at the desired initial moisture content were prepared by adding calculated amounts of distilled water and sealing in separate polyethylene bags. The drying thin-layer kinetics tests were determined at the following initial moisture contents: 4.2 , $14.3,26.4$, and $33.5 \%$ d.b. for seeds and at 5.0, 13.2, and 23.8\% d.b. for kernels. Moisture content was determined by the oven drying method described in ASAE Standard S352.1 ${ }^{[7]}$ at $130^{\circ} \mathrm{C}$ oven temperature during $3 \mathrm{~h}$. All moisture contents were determined using two replications.

\section{Experimental Tests}

A laboratory thin-layer dryer (Fig. 1) was used to evaluate the drying rates of high oleic sunflower seeds and kernels. A fan drove the air through a heating unit towards the drying chamber in which the seeds were spread on a $0.0232 \mathrm{~m}^{2}$ removable tray. The samples used for the experiments consisted in a single layer of seeds which thickness was less than $0.01 \mathrm{~m}$. The hot air flowed uniformly across the sample at constant velocities in the range of 0.28 to $0.31 \mathrm{~m} / \mathrm{s}$, controlled by a damper and measured on a calibrated orifice plate. These air velocities were selected because thin-layer drying of seeds is independent of air 


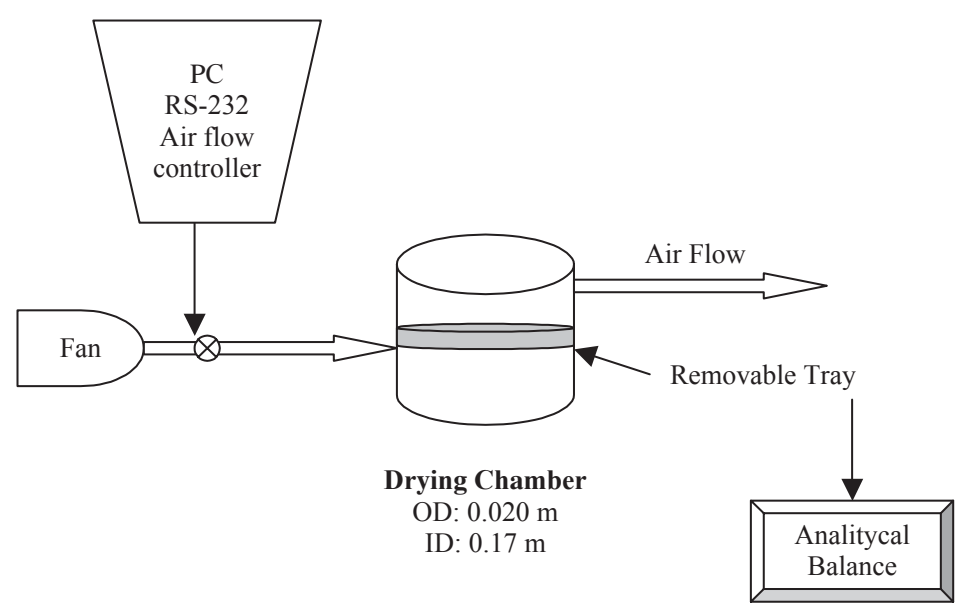

Figure 1 Convective hot air drying apparatus.

velocity when this is higher than $0.2 \mathrm{~m} / \mathrm{s}^{[8,9]}$ Before each run, the air was heated at the desired dry bulb temperature through electrical resistances. Relative humidity was measured by using an aspirated psychrometer (Paspst, Type $8550 \mathrm{VW}$ ). In order to stabilize the conditions before each test the equipment was previously run for $1 \mathrm{~h}$.

\section{Experimental Design}

Drying runs were carried out at five air temperatures $\left(25,40,60,75\right.$, and $\left.90^{\circ} \mathrm{C}\right)$ and at the initial moisture contents described previously. The moisture loss was registered along time intervals of 2, 4, 6, 10, and 15 min and each test continued during two hours. The equilibrium moisture contents for each temperature and equilibrium relative humidity were obtained from a previous work ${ }^{[10]}$ using the modified GAB model Eq. (1) that includes the dependence of the GAB parameters with temperature:

$$
X_{e}=\frac{A o \cdot \exp (A 1 / T) \cdot B_{G} \cdot C_{G} \cdot E R H}{\left(1-B_{G} \cdot E R H\right) \cdot\left(1-B_{G} \cdot E R H+B_{G} \cdot C_{G} \cdot E R H\right)},
$$

where $\mathrm{X}_{\mathrm{e}}$ is the equilibrium moisture content, $\mathrm{A}_{\mathrm{o}}, \mathrm{A}_{1}, \mathrm{~B}_{\mathrm{G}}$, and $\mathrm{C}_{\mathrm{G}}$ are the estimated $\mathrm{GAB}$ coefficients for seeds and kernels and ERH is the equilibrium relative humidity of air into the drying chamber. Table 1 shows the values of Xe used at each experimental condition.

\section{Diffusivity Equations}

The equation used to obtain the diffusion coefficient was derived from Fick's second law of diffusion:

$$
\frac{\partial X}{\partial \mathrm{t}}=\mathrm{D} \nabla^{2} \mathrm{X}
$$


Table 1 Equilibrium moisture content $X_{e}$ for high oleic sunflower seeds and kernels at the experimental conditions used in the present study.

\begin{tabular}{lccccc}
\hline & \multicolumn{5}{c}{ Xe [g water/g dry solid] } \\
\cline { 2 - 5 } $\mathrm{T}\left[{ }^{\circ} \mathrm{C}\right]$ & 25 & 40 & 60 & 75 & 90 \\
\hline Seed & $2.80(24 \%)^{\mathrm{a}}$ & $1.81(11 \%)$ & $0.86(3.6 \%)$ & $0.52(1.9 \%)$ & $0.40(1.4 \%)$ \\
Kernel & $2.45(24 \%)$ & $1.94(11 \%)$ & $1.49(4.8 \%)$ & $1.00(1.7 \%)$ & $0.89(1.6 \%)$ \\
\hline
\end{tabular}

${ }^{\mathrm{a}}$ Values between parenthesis represent Equilibrium Relative Humidity (ERH).

where $\mathrm{X}$ is the local moisture content (dry basis). This shape of Eq. (2) implies the neglecting of shrinkage during drying, an usual assumption for low moisture content seeds. The analytical solution of Eq. (2) for the case of sphere, assuming unidimensional moisture movement without volume change, constant diffusivity, uniform initial moisture distribution and negligible external resistances results ${ }^{[11]}$ :

$$
X=\frac{X-X_{e}}{X_{o}-X_{e}}=\frac{6}{\pi^{2}} \sum_{n=1}^{\infty} \frac{1}{n^{2}} \exp \left[-n^{2} \pi^{2} \frac{D t}{r^{2}}\right]
$$

where $\mathrm{X}^{\prime}$ is the average moisture ratio; $\mathrm{X}_{\mathrm{o}}$ is the initial moisture content; $\mathrm{r}$ is the equivalent radius of the seed or kernel; $t$ is time; and $\mathrm{D}$ is the diffusion coefficient. For short times, a diffusional equation based on semi-infinite medium concepts and the expansion of Eq. (3) in Mc Laurin series was developed ${ }^{[12]}$ :

$$
X: \frac{X-X_{e}}{X_{o}-X_{e}}=1-\frac{2}{\pi} a_{V} \sqrt{D . t}+\frac{f}{2} a_{V}^{2} D t,
$$

where $\mathrm{f}=0.661$; and $\mathrm{a}_{\mathrm{v}}=3 / \mathrm{R}$ for spheres. This approximation is valid for $0.2<\mathrm{X}^{\prime}<1$ and $0<\mathrm{z}<1$ with $\mathrm{z}=\mathrm{a}_{\mathrm{v}} \sqrt{ } \mathrm{Dt}$ and its accuracy has been tested against experimental data of wheat ${ }^{[13]}$ and quinoa ${ }^{[14]}$ drying. Experimental values of moisture ratio $X^{\prime}$ between 0.2 and 1.0 were used to adjust the drying data ( $\mathrm{X}^{\prime}$ versus $\left.\mathrm{t}\right)$ to Eq. 4 so as to find the diffusion coefficient at each temperature. The dependence of moisture diffusivity with temperature was verified using the well known Arrhenius-type relationship:

$$
\mathrm{D}=\mathrm{D}_{\mathrm{o}} \mathrm{e}^{\frac{-\mathrm{E}_{\mathrm{a}}}{\mathrm{RT}}}
$$

where Do is the Arrhenius factor $\left(\mathrm{m}^{2} / \mathrm{s}\right)$; Ea is the activation energy for moisture diffusion $(\mathrm{kJ} / \mathrm{kmol})$; $\mathrm{R}$ is the ideal gas constant $(\mathrm{kJ} / \mathrm{kmol} . \mathrm{K})$; and $\mathrm{T}$ is the absolute temperature $(\mathrm{K})$.

A relationship between diffusion coefficient and kinetic parameter $\mathrm{k}$ of Page equation was reported for a spherical Al-Ni catalyst. ${ }^{[15]}$ The simplicity of this model will be used to evaluate the moisture diffusion in seeds and kernels of high oleic sunflower taking into account the accuracy of the Page model for the prediction of thin-layer drying rates demonstrated in a previous work. ${ }^{[16]}$ A nonlinear module of Systat Statistical Software ${ }^{[17]}$ was used to calculate the diffusion coefficient from Eq. (4). The statistics used to evaluate 
the goodness of the adjustments were the standard error of the estimated value (SE) calculated as:

$$
\mathrm{SE}=\sqrt{\frac{\sum(\mathrm{Y}-\mathrm{Y} \cdot)^{2}}{\mathrm{df}}},
$$

where $\mathrm{Y}$ and $\mathrm{Y}^{\prime}$ are the experimental and predicted values of the variable studied; the mean relative percent deviation $(\mathrm{P})$ calculated as:

$$
\mathrm{P}=\frac{100}{\mathrm{~N}} \sum \frac{|\mathrm{Y}-\mathrm{Y} \cdot|}{\mathrm{Y}}
$$

and the coefficient of determination $\left(\mathrm{R}^{2}\right)$ at a level of $95 \%$ of confidence.

\section{RESULTS AND DISCUSSION}

To obtain the values of $\mathrm{D}$ valid for the initial drying period of interest, in industrial drying, Eq. (4) was fitted to the experimental thin layer drying data, using the equivalent radius of $0.0054 \mathrm{~m}$ for seed and $0.0039 \mathrm{~m}$ for kernel ${ }^{[18]}$ and assuming that initial moisture content has no effect on moisture diffusivity. These calculated values are shown in Table 2, where $D_{s}$ and $D_{k}$ indicate the moisture diffusivities in seed and kernel, respectively. The table also shows the corresponding standard errors for moisture diffusivity at each drying air temperature and the coefficients of determination of the fitting of Eq. (4) by using the non-linear method. Previously determined diffusivities in sunflower kernels, using Eq. (3), were reported ${ }^{[5]}$ with a value of $0.7 \times 10^{-10} \mathrm{~m}^{2} / \mathrm{s}$ at $40^{\circ} \mathrm{C}$, very close to that reported in this work at the same temperature $\left(0.667 \times 10^{-10} \mathrm{~m}^{2} / \mathrm{s}\right)$.

Analysis of variance was used to estimate the significance of the effect of the initial moisture content on the diffusion coefficient. Results of the ANOVA demonstrated that initial moisture content has no significant effect on water diffusion in high oleic sunflower seeds and kernels at a 95\% level of confidence, giving values of Snedecor function $\mathrm{F}$ of 11.09 and 14.72 for seeds and kernels respectively, against $\mathrm{F}_{0.05,3,4}=9.12$.

The Arrhenius type-relationship Eq. (5) was proposed to fit the variation with temperature of the experimental values of moisture diffusivity. Figure 2 shows the relationships obtained, where the values of constants and coefficients of determination are presented in Table 3. The activation energy (without taking into account the effect of the

Table 2 Average values (for all runs from different initial moisture contents) of moisture diffusion coefficients in seeds $\left(D_{s}\right)$ and kernels $\left(D_{k}\right)$ at different drying air temperatures, obtained through adjustment of experimental

\begin{tabular}{|c|c|c|c|c|c|c|}
\hline \multirow[b]{2}{*}{ Temperature $\left({ }^{\circ} \mathrm{C}\right)$} & \multicolumn{3}{|c|}{$\mathrm{D}_{\mathrm{s}}\left(\mathrm{m}^{2} / \mathrm{s}\right)$} & \multicolumn{3}{|c|}{$\mathrm{D}_{\mathrm{k}}\left(\mathrm{m}^{2} / \mathrm{s}\right)$} \\
\hline & Value & Std. error & $\mathrm{R}^{2}$ & Value & Std. error & $\mathrm{R}^{2}$ \\
\hline 25 & $0.84710^{-10}$ & $4.81 .10^{-12}$ & 0.972 & $0.37010^{-10}$ & $2.12 .10^{-12}$ & 0.913 \\
\hline 40 & $1.30610^{-10}$ & $6.88 .10^{-12}$ & 0.939 & $0.66710^{-10}$ & $5.03 .10^{-12}$ & 0.970 \\
\hline 60 & $2.81310^{-10}$ & $6.77 .10^{-12}$ & 0.904 & $1.05510^{-10}$ & $3.45 .10^{-12}$ & 0.989 \\
\hline 75 & $4.04010^{-10}$ & $6.90 .10^{-12}$ & 0.977 & $1.33310^{-10}$ & $4.17 .10^{-12}$ & 0.986 \\
\hline 90 & $7.25610^{-10}$ & $4.63 .10^{-12}$ & 0.974 & $2.43110^{-10}$ & $6.60 .10^{-12}$ & 0.967 \\
\hline
\end{tabular}
data to Eq. (4). 


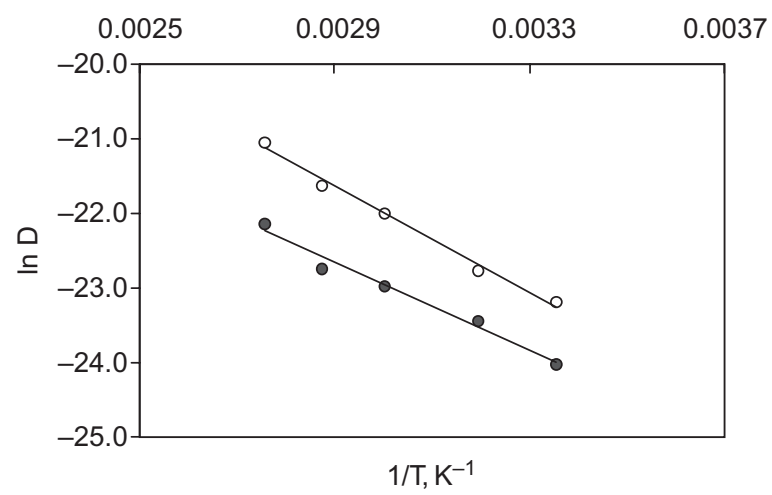

Figure 2 Relationship between diffusion coefficient of seed $D_{s}$ (white symbols) and kernel $D_{k}$ (black symbols) and absolute temperature.

Table 3 Constants and correlation coefficients obtained for the parameters of Eq. (5) for whole seed and kernel.

\begin{tabular}{lcc}
\hline Coefficient & Whole seed & Kernel \\
\hline $\mathrm{D}_{0}\left(\mathrm{~m}^{2} / \mathrm{s}\right)$ & $1.785910^{-4}$ & $6.184810^{-7}$ \\
$\mathrm{E}_{\mathrm{a}}(\mathrm{kJ} / \mathrm{mol})$ & 30.698 & 24.009 \\
Correlation $\left(\mathrm{R}^{2}\right)$ & 0.996 & 0.980 \\
\hline
\end{tabular}

initial moisture content) in high oleic sunflower seeds resulted $30.7 \mathrm{~kJ} / \mathrm{mol}, 22 \%$ higher than in kernel $(24.0 \mathrm{~kJ} / \mathrm{mol})$. This behavior can be related to previous results ${ }^{[5]}$ that found that moisture diffuses between about two and four times faster through the hull than through the kernel.

A kinetic model based on the Page equation Eq. (8), with the parameters $\mathrm{k}$ and $\mathrm{n}$ temperature-dependent Eqs. (9) and (10), was proved previously ${ }^{[16]}$ as a good model for thin-layer drying rates for whole sunflower seeds:

$$
\mathrm{X} \cdot=\mathrm{e}^{-\mathrm{kt} \mathrm{n}^{\mathrm{n}}}
$$

where the parameters $\mathrm{k}$ and $\mathrm{n}$ are temperature dependent according the following relationships:

$$
\begin{aligned}
& \mathrm{k}=\mathrm{AT}^{\mathrm{B}}, \text { and } \\
& \mathrm{n}=\mathrm{E}+\mathrm{FT} .
\end{aligned}
$$

The values of A, B, E and F and the corresponding statistics are described in Table 4. A first analysis between the values of experimental diffusivities in seeds and kernels and the kinetic parameter of Page equation $\mathrm{k}$ showed a non linear dependence of expontential 
Table 4 Coefficients of Eq. (8) for the temperature dependence of Page parameters $\mathrm{k}$ and $\mathrm{n}$ for high oleic sunflower seed and kernel.

\begin{tabular}{lccc}
\hline & Value & Standard error & $\mathrm{R}^{2}$ \\
\hline Seed & & & \\
A & 0.0072525 & 0.000068 & \\
B & 0.6876774 & 0.008260 & $>0.99$ \\
E & 0.5373581 & 0.006086 & \\
F & 0.0027026 & 0.000136 & \\
Kernel & & & $>0.98$ \\
A & 0.0123133 & 0.003907 & \\
B & 0.5374414 & 0.060078 & \\
E & 0.5902078 & 0.040468 & \\
F & 0.0023532 & 0.000647 & \\
\hline
\end{tabular}

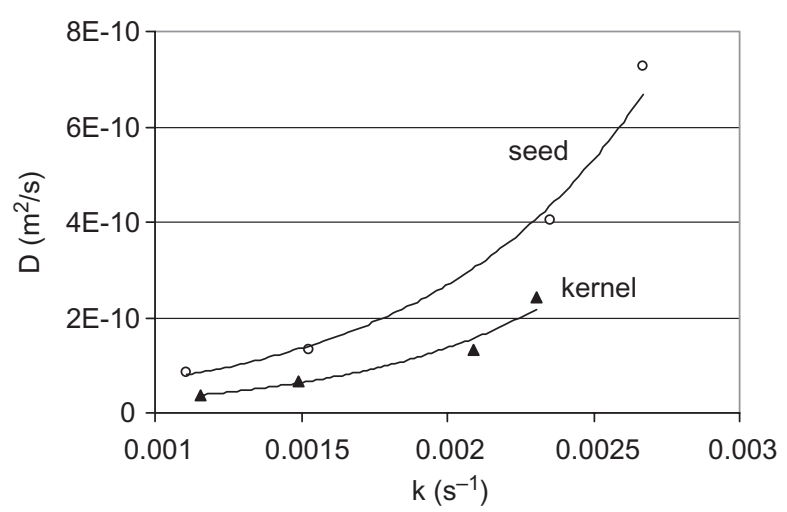

Figure 3 Relationship between moisture diffusivity in seed and kernel obtained from equation 5 and the Page kinetic parameter.

form as can be observed from Fig. 3. The results of the best fit analyzed for four air temperatures tested: $25,40,75$, and $90^{\circ} \mathrm{C}$ (the remainder temperature $60^{\circ} \mathrm{C}$ was used to test the adjustment) are summarized in the following expressions:

$$
\begin{aligned}
& \mathrm{D}_{\mathrm{sk}}=0.1058 \cdot 10^{-10} \cdot \exp (1576.9 \cdot \mathrm{k}), \text { and } \\
& \mathrm{D}_{\mathrm{kk}}=0.3766 \cdot 10^{-11} \cdot \exp (1786.0 \cdot \mathrm{k}),
\end{aligned}
$$

where $D_{\text {sk }}$ and $D_{k k}$ mean the diffusion coefficient (in $\mathrm{m}^{2} / \mathrm{s}$ ) in seed and in kernel, respectively, as a function of Page parameter $\mathrm{k}$ (with $\mathrm{k} \mathrm{in} \mathrm{s}^{-1}$ ). The corresponding standard errors of the estimated parameters and the coefficients of determination $\mathrm{R}^{2}$ are tabulated in Table 5. Taking into account that the statistics showed a good adjustment, Eqs. (11) and (12) was used to evaluated de diffusion coefficient at $60^{\circ} \mathrm{C}$ to be compared with the experimental value at this temperature. Diffusion of water in seed, $\mathrm{D}_{\mathrm{sk}}$ calculated by using 
Table 5 Values and statisticals of the coefficients of the Eqs. (11) and (12) at 95\% level of confidence.

\begin{tabular}{lccr}
\hline & Parameter & Standard error & $\mathrm{R}^{2}$ \\
\hline Seed & & & \\
$\quad$ Preexponential factor & $0.1058 .10^{-10}$ & $0.455 .10^{-11}$ & 0.993 \\
$\quad$ Exponential factor & 1576.9 & 167.6 & \\
Kernel & & & 0.963 \\
$\quad$ Preexponential factor & $0.3766 .10^{-11}$ & $0.3428 .10^{-11}$ & \\
$\quad$ Exponential factor & 1786.0 & 412.67 & \\
\hline
\end{tabular}

Eq. (11) resulted $2.5567 .10^{-10} \mathrm{~m}^{2} / \mathrm{s}$ (absolute error from experimental value resulted $9.1 \%$ ) and diffusion of water in kernel $\mathrm{D}_{\mathrm{kk}}$ obtained from Eq. (12) resulted 1.0308.10 $\mathrm{m}^{2} / \mathrm{s}$ (absolute error from experimental value resulted $2.3 \%$ ). This arrangement shows that Eqs. (11) and (12) resulted a good and simple tool to evaluate diffusion of water in high oleic sunflower when kinetic parameter of Page equation is available.

If the diffusion coefficients determined with Eqs. (11) and (12) are plotted against 1/T, the activation energies can be found in a similar way as previouly, by using the Arrhenius model. The activation energy obtained by applying Eq. (5) and using values of $D_{\text {sk }}$ calculated from Eq. (11) (with k from Eq. (9)), resulted $29.5 \mathrm{~kJ} / \mathrm{mol}\left(\mathrm{R}^{2}=0.992\right)$, with an absolute error of $3.9 \%$ from the activation energy obtained from $\mathrm{D}_{\mathrm{s}}$ values obtained from equation $4(30.7 \mathrm{~kJ} / \mathrm{mol})$. In kernel, the activation energy obtained by applying Eq. (5) and using values of $\mathrm{D}_{\mathrm{kk}}$ from Eq. (12) resulted $24.2 \mathrm{~kJ} / \mathrm{mol}\left(\mathrm{R}^{2}=0.979\right)$, with an absolute error of $0.8 \%$ compared with the activation energy obtained from $\mathrm{D}_{\mathrm{k}}$ values obtained from Eq. (4) $(24.0 \mathrm{~kJ} / \mathrm{mol})$. These differences can be assumed as negligible and underline the option to use Eqs. (11) and (12) to calculate diffusion coefficients.

Drying kinetics curves ( $\left.\mathrm{X}^{\prime} \mathrm{vs} \mathrm{t}\right)$ with $\mathrm{X}^{\prime}$ calculated from Eq. 4 with diffusion coefficient obtained from Eqs. (11) and (12) (for seeds and kernels respectively) were tested against the experimental ones. Figures 4 and 5 show the results obtained for the drying of seeds and kernels, respectively. The goodness of the adjustment was evaluated through the standard error of the estimated value (SE) and the mean relative percent deviation

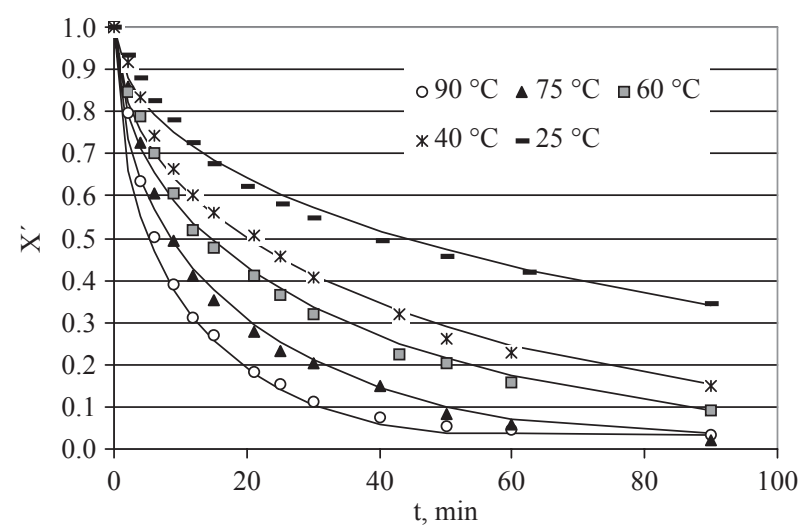

Figure 4 Moisture ratio of high oleic sunflower seeds. Experimental values are represented through symbols while the proposed model based on diffusion coefficient calculated with $\mathrm{k}$ parameter of Page model is shown through lines. 


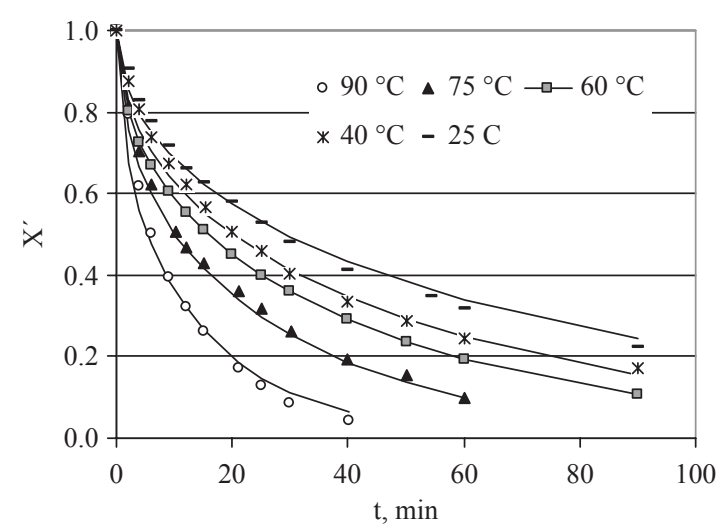

Figure 5 Moisture ratio of high oleic sunflower kernels. Experimental values are represented through symbols while the proposed model based on diffusion coefficient calculated with $\mathrm{k}$ parameter of Page model is shown through lines.

Table 6 Evaluation of the goodness of the adjustment of experimental thin-layer drying test ( $\mathrm{X}^{\prime}$ vs $\left.\mathrm{t}\right)$ with Equations 11 and 12.

\begin{tabular}{llllll}
\hline & \multicolumn{2}{c}{$\mathrm{P}$} & & \multicolumn{2}{c}{ SE } \\
\cline { 2 - 3 } $\mathrm{T}\left({ }^{\circ} \mathrm{C}\right)$ & Seed & Kernel & & Seed & Kernel \\
\hline 90 & 5.551 & 8.481 & 0.162 & 0.141 \\
75 & 6.322 & 4.216 & 0.162 & 0.086 \\
60 & 4.956 & 2.355 & 0.113 & 0.068 \\
40 & 4.151 & 3.531 & 0.138 & 0.093 \\
25 & 3.140 & 3.316 & 0.100 & 0.081 \\
\hline
\end{tabular}

calculated from Eqs. (6) and (7), respectively. Table 6 summarizes the results obtained. The proposed model showed good agreement with respect to the experimental thin-layer drying tests. The mean relative percent deviation resulted lower than 6.322 for seeds and than 8.481 for kernels. The standard error of the estimated value, that is moisture ratio $\mathrm{X}^{\prime}$, resulted lower than 0.162 for seeds and lower than 0.141 for kernels.

\section{CONCLUSIONS}

Equation (4), based on the Becker model, showed adequate for the fitting of experimental data of thin layer drying of high oleic sunflower seeds and kernels in the range of temperature from 25 to $90^{\circ} \mathrm{C}$ and for different water contents. Highly accurate values for diffusion coefficients were obtained using this method. Page model also fitted adequately experimental data for thin layer drying data for whole seeds and kernels. The kinetic parameters $\mathrm{k}$ and $\mathrm{n}$ could be satisfactorily related to temperature. Based on these previous results, a new model based on the kinetic parameter of Page equation was proposed as a simple tool to predict the diffusion of water in high oleic sunflower seeds and kernels. The goodness of the adjustment evaluated through the mean relative percent deviation and the standard error of the estimated value demonstrated that the proposed model could be used for prediction of diffusion behavior when kinetics drying has previously studied. 


\section{NOMENCLATURE}

$\begin{array}{ll}A, B, E, F & \text { Parameters of the modified Page equation } \\ A_{o}, A_{1}, B_{G}, C_{G} & \text { Coefficients of GAB equation } \\ D & \text { Diffusion coefficient, } \mathrm{m}^{2} / \mathrm{s} \\ D_{k} & \text { Diffusion coefficient in kernel based on equation } 5 \\ D_{k k} & \text { Diffusion coefficient in kernel based on kinetic Page parameter, } \mathrm{m}^{2} / \mathrm{s} \\ \mathrm{D}_{\mathrm{o}} & \text { Arrhenius factor, } \mathrm{m}^{2} / \mathrm{s} \\ \mathrm{D}_{\mathrm{s}} & \text { Diffusion coefficient in seed based on equation } 5, \mathrm{~m}^{2} / \mathrm{s} \\ \mathrm{D}_{\mathrm{sk}} & \text { Diffusion coefficient in seed based on kinetic Page parameter, } \mathrm{m}^{2} / \mathrm{s} \\ \mathrm{d} . \mathrm{b} . & \text { Dry basis } \\ \mathrm{E}_{\mathrm{a}} & \text { Activation energy, } \mathrm{kJ} / \mathrm{mol} \\ \mathrm{k} & \text { Page kinetic parameter, } \mathrm{s}^{-1} \\ \mathrm{n} & \text { Page parameter, dimensionless } \\ \mathrm{P} & \text { Mean relative percent deviation } \\ \mathrm{R} & \text { Gas constant, kJ/(mol K) } \\ \mathrm{R}^{2} & \text { Coefficient of determination } \\ \mathrm{RH} & \text { Relative humidity of air, } \% \text { d.b. } \\ \mathrm{r} & \text { Equivalent radius, } \mathrm{m} \\ \mathrm{SE} & \text { Standard error of the estimated value } \\ \mathrm{T} & \text { Temperature, } \mathrm{K} \\ \mathrm{t} & \text { Time, } \mathrm{s} \\ \mathrm{X} & \text { Moisture content, d.b. } \\ \mathrm{X}^{\prime} & \text { Moisture ratio, dimensionless } \\ \mathrm{X}_{\mathrm{e}} & \text { Equilibrium moisture content, d.b. } \\ \mathrm{X}_{\mathrm{o}} & \text { Initial moisture content, d.b. } \\ \mathrm{Y} & \text { Experimental data } \\ \mathrm{Y}^{\prime} & \text { Predicted values of the variable studied } \\ & \end{array}$

\section{REFERENCES}

1. Garcés, R.; García, J.M.; Mancha, M. Lipid characterization in seeds of a high oleic acid sunflower mutant. Phytochemistry 1989, 8 (10), 2597-2600.

2. Fitch Haumann, B. Aceite de girasol modificado. La clave para el futuro [Oil from modified sunflower. The key for future]. Aceites y Grasas 1998, 8 (30), 81-92.

3. Bax, M.M.; Gely, M.C.; Santalla, E.M. Prediction of Crude Sunflower Oil Deterioration after Seed Drying and Storage Processes. Journal of American Oil Chemists' Society 2004, 81 (5), 511-515.

4. Zogzas, N.P.; Maroulis, Z.B.; Marinos-Kouris, D. Moisture Diffusivity Methods of Experimental Determination. A review. Drying Technology 1994, 12 (3), 483-515.

5. Rovedo, C.; Aguerre, R.; Suárez, C. Moisture diffusivities of sunflower seed components. International Journal of Food Science asnd Technology. 1993, 28, 159-168.

6. Joshi, D.C.; Das, S.K.; Mukherjee, R.K. Physical properties of pumpkinseeds. Journal of Agricultural Engineering Research 1993, 54 (3), 219-229.

7. American Society of Agricultural Engineers. Standard Engineering Practices Data. American Society of Agricultural Engineers, eds., $46^{\text {th }}$ ed., ASAE Standards; ASAE: 1999, p. 567.

8. Henderson, S.M.; Pabis, S. Grain drying theory IV, The effect of airflow rate on the drying index. Journal of Agricultural Engineering Research 1962, 85-89.

9. Hutchinson, D.; Otthen, L. Thin-layer air drying of soybeans and white beans. Journal of Food Technology 1983, 18, 507-522.

10. Santalla, E.; Mascheroni, R. Equilibrium Moisture Characteristics of High Oleic Sunflower Seeds and Kernels. Drying Technology. 2003, 21 (1), 147-163. 
11. Crank, J. The mathematics of Diffusion, $2^{\text {nd }}$ ed. Oxford University Press, Inc.: New York; 1975; $85-86$.

12. Becker, H.A. A Study of Diffusion in Solids of Arbitrary Shape, with Application to the Drying of the Wheat Kernel. Journal of Applied Polymer Science 1959, I (2), 212-226.

13. Giner, S.A.; Mascheroni, R.H. Diffusive drying kinetics in wheat. Part II: Applying the simplified analytical solution to experimental data. Journal of Agricultural Engineering Research 2002, 81 (1), 85-97.

14. Gely, M.A.; Santalla, E.M. Moisture diffusivity in quinoa (Chenopodium quinoa Willd.) seeds: Effect of air temperature and initial moisture content of seeds. Journal of Food Engineering 2007, 78(3), 1029-1033.

15. Sander, A.; Tomas, S.; Skansi, D. The influence of air temperature on effective diffusion coefficient of moisture in the falling rate period. Drying Technology 1998, 16 (7), 1487-1499.

16. Santalla, E.; Mascheroni, R. In Thin-layer drying models for high oleic sunflower seeds, Proceedings of the 2nd Inter-American Drying Conference, Veracruz, México, July 8-10, 2001, Krzysztof N. Waliszewski, ed. 307-315.

17. Wilkinson, L. SYSTAT: The System for Statistics. SYSTAT, Inc., Evanston, IL, 1990, 323-335.

18. Santalla, E.; Mascheroni, R. Physical Properties of High Oleic Sunflower Seeds. Food Science \& Technology International 2003, 9 (6), 435-442. 